\title{
GPPS-CH-2020-129
}

\section{COMPUTATIONAL ANALYSIS OF A WELLS TURBINE FOR WAVE POWER GENERATION}

\author{
Achileas Krikas \\ Dept. of Mechanical \\ Engineering, University of \\ Western Macedonia \\ achilles.mech@hotmail.com \\ Kozani, Greece
}

\author{
Kyriakos Vadiadis \\ Dept. of Mechanical \\ Engineering, University of \\ Western Macedonia \\ kvafiadis@uowm.gr \\ Kozani, Greece
}

\author{
Antonios Tourlidakis \\ Dept. of Mechanical \\ Engineering, University of \\ Western Macedonia \\ atourlidakis@uowm.gr \\ Kozani, Greece
}

\begin{abstract}
Sea waves are an important renewable energy source, which, if appropriately exploited, can make a significant contribution to the electrical supply of areas surrounded by the sea. A number of technologies have already been proposed, studied and in some cases tested under real conditions. One of these technologies is the combination of an Oscillating Water Column (OWC) and a Wells turbine. The main purpose of this research is the design and analysis of a Wells turbine based OWC system and the development of an experimental facility in order to study this type of turbines under various simulated wave conditions. The paper presents the design procedure and the computational analysis of a Wells turbine for various air inlet flow velocities and rotor speeds. Flow field characteristics at steady and unsteady conditions are analysed using Computational Fluid Dynamics (CFD) and related to the rotor performance. The performance of the turbine was found to reach an efficiency of $60 \%$ at $4000 \mathrm{rpm}$ before stall. The computational results are compared with corresponding test data from an experimental configuration which was built in order to investigate the turbine behaviour under oscillating inlet flow conditions. The computational and experimental results both demonstrate similar trends and their analysis facilitates the in depth understanding of the turbine operation.
\end{abstract}

\section{INTRODUCTION}

Wave energy is an important renewable energy source that may have a significant contribution to the electrical energy supply, especially to areas surrounded by the sea. A number of technologies have been proposed and tested under real conditions.

A review of self-rectifying turbines for wave energy conversion is provided by Setoguchi and Takao (2006. A comprehensive review of OWC technologies and air turbines is presented by Falcao and Henriques (2016). This is followed by a survey of theoretical, numerical and experimental modelling techniques of OWC converters. The turbines used in OWCs are self-rectifying as their rotational direction remains unchanged regardless of the direction of the air flow. Several types of such special turbines have been developed. The axial flow Wells turbine is the most popular type of self-rectifying turbines, but alternative types, such as self-rectifying impulse turbines, have also been proposed, investigated and employed.

This type of turbines were initially developed based on theoretical analysis and steady-state laboratory tests, and later with the use of computational fluid dynamics (CFD) methods which have become a powerful tool for their analysis, design and optimisation. An extensive review on recent developments in the CFD modelling, geometry optimisation, and performance enhancement and perspectives on the utilization of CFD methods for OWC axial-flow turbines, is presented by Y.Cui et al (2019).

One of the most effective technologies is the combination of an Oscillating Water Column (OWC) and a self-rectifying Wells turbine which has a minimum requirement of flow guiding. The axial flow Wells turbine invented in 1976 by Dr Alan A. Wells (1976). Wells turbines are based on the development of aerodynamic lift force on rotor blades shaped as symmetrical cross section aerofoils whose chordal plane is perpendicular to the axis of rotation. Several improvements of the axial-flow Wells turbine have been developed or proposed: with or without guide vanes, multistage, bi-plane, contra-rotating and with rotor blades of variable-pitch. 
A Wells turbine's unique property is that the rotor can accept inflow from both inlet and outlet directions without changing the rotation direction. OWC devices consist of a piston which floats over the sea surface and thus oscillates due to the sea wave movement. The piston lies inside a pipe which is connected with the Wells turbine shroud. The periodic movement of the wave compresses and decompresses the air above the piston, which is led to pass through the turbine, which in turn can be connected to a generator. The Wells turbine is one of the most well-known and efficient self-rectifying turbines. In its simplest form, the rotor consists of symmetrical blades which are placed perpendicular to the axis of rotation (Figure 1.a), without a camber angle, with the leading and trailing edge forming the same angle $\lambda$ with the radial direction and without inlet guide vanes. By using symmetrical blades, the tangent force on the blade has the same direction regardless of the direction of air flow. Figure 1.b shows the Wells turbine velocity triangles, presented in their general form with inlet swirl. In the case where there are no inlet guide vanes, the incoming flow is axial and the angle $\beta_{1}$ equals to $\pi / 2$.

Different geometrical modifications were carried out by researchers to improve the performance characteristics as well as the operating range of the turbine. In this work, two simple Wells turbine geometries, Model A and Model B, were designed and analyzed computationally, under both steady and time dependent flow conditions. Model B was also evaluated experimentally. The detailed characteristics of the two designs are presented in Table 1.

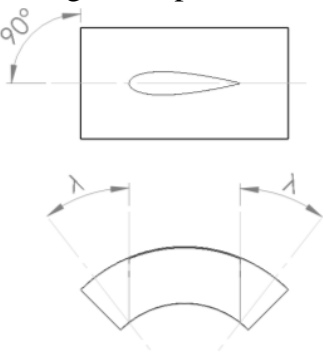

(a)

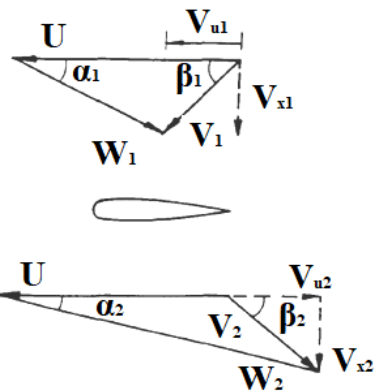

(b)

Figure 1 a) Wells turbine model b) inlet and outlet velocity triangles of a Wells turbine blade airfoil (with inlet swirl)

Table 1 Geometrical features of the Wells turbine rotor models

\begin{tabular}{|c|c|c|}
\hline Geometry & Model A & Model B \\
\hline Airfoil & NACA 0021 & NACA 0021 \\
\hline Number of blades & 4 & 4 \\
\hline Chord length (mm) & 100 & 100 \\
\hline Hub to tip ratio & 0.619 & 0.562 \\
\hline Solidity & 0.598 & 0.566 \\
\hline Hub diameter $(\mathrm{mm})$ & 163 & 163 \\
\hline Tip diameter $(\mathrm{mm})$ & 263 & 288 \\
\hline Aspect ratio & 0.5 & 0.625 \\
\hline Blade tip clearance $(\mathrm{mm})$ & 1 & 1 \\
\hline
\end{tabular}

\section{METHODOLOGY}

An unsteady Reynolds-Averaged Navier-Stokes (RANS) approach with the k- $\omega$ Shear Stress Transport (SST) turbulence model (Menter, 1994) are used in this work with the use of the commercial ANSYS CFX code. The SST model which is based on the two equations k- $\omega$ model takes into account the turbulence shear stress transport. In conjunction with the automatic wall treatment used in ASNYS CFX and the use of an appropriately fine computational grid with $\mathrm{y}^{+} \approx 1$ the turbulence model provides high precision predictions on the flow separation under adverse pressure conditions.

The simulations under steady state conditions were carried out for three different rotational speeds 2000,3000 and $4000 \mathrm{rpm}$ and three flow velocities from 2.5 to $17.5 \mathrm{~m} / \mathrm{s}$ in order to provide a parametric study of the rotor performance. Model A was also analysed for a rotational speed of $4500 \mathrm{rpm}$ and flow velocity from 5 to $14 \mathrm{~m} / \mathrm{s}$ in order to compare its performance to the results of the simulations were also carried out by other researchers (Dhanasekaran et al., 2005; Carija, 2012). Model B was analysed under unsteady conditions and especially for two different setups cases. For the first case the rotational speed varied from 0 to $4000 \mathrm{rpm}$ for eight different flow velocities from 2.5 to $17.5 \mathrm{~m} / \mathrm{s}$. The second case concerned simulations for steady rotational speed of $2000 \mathrm{rpm}$ and a sinusoidal variation of the inflow velocity which was carried out for various frequencies $(<1 \mathrm{~Hz})$ and wave lengths. This case aimed to provide insight on the starting behaviour of the rotor and the hysteresis phenomenon. The computational domain dimensions are presented in Fig. 2. A fixed uniform velocity inlet and a fixed outlet pressure were applied as boundary conditions (Fig. 2.b) for the steady state runs. 


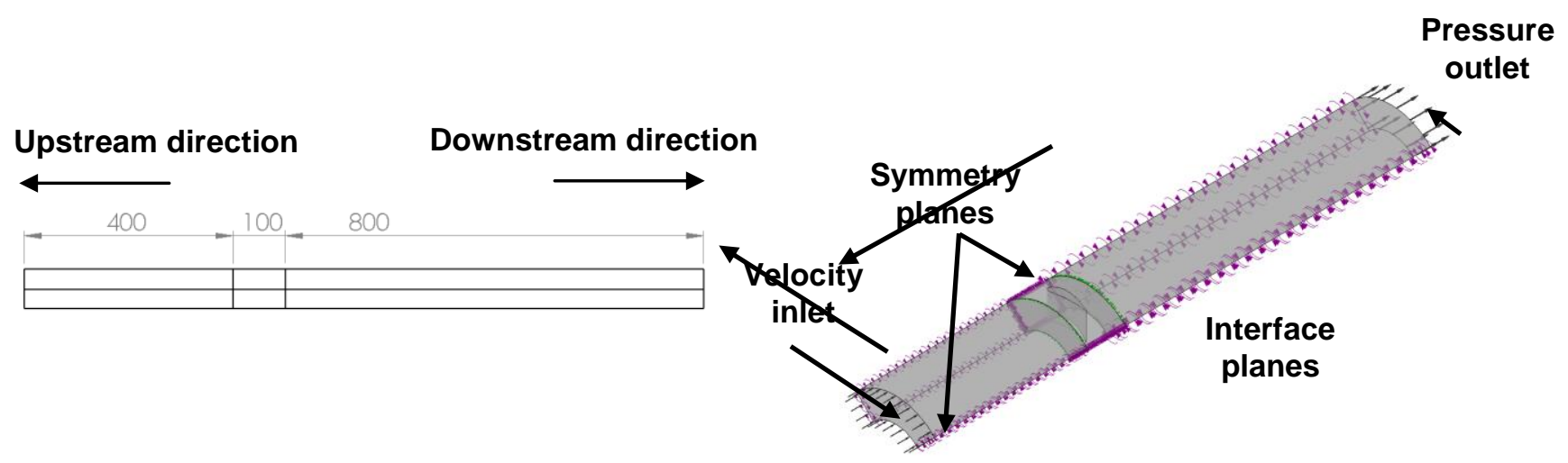

(a)

(b)

Figure 2: a) Computational domain dimensions b) boundary conditions applied

The computational domain consists of three sub-domains and the frozen rotor interface is applied on the faces that connect each sub-domain. By applying symmetry boundary conditions on the appropriate planes only the $1 / 4$ of the geometry is taken under consideration in this study. A grid independence study was carried out with coarser meshes. The results presented here, concern only the final grid independent solution. The grid consists of about 10 million cells and it is appropriately refined around the walls in order to provide improved boundary layer resolution (Fig. 3). The tip clearance region, with a height of $1 \mathrm{~mm}$, was appropriately discretised with a fine mesh over the blade, as tip leakage strongly influences performance and affects the process of stall development. The turbine performance under steady state conditions is evaluated by means of three non-dimensional parameters, namely the torque coefficient $\left(\mathrm{C}_{\mathrm{T}}\right)$, the pressure coefficient $\left(\mathrm{C}_{\mathrm{p}}\right)$ and the efficiency $(\eta)$.

$$
\begin{aligned}
\mathrm{C}_{\mathrm{T}} & =\frac{T}{\rho \cdot \omega^{2} \cdot r_{t}^{5}} \\
\mathrm{C}_{\mathrm{p}} & =\frac{\Delta p}{\rho \cdot \omega^{2} \cdot r_{t}^{2}} \\
\eta & =\frac{T \cdot \omega}{\Delta p \cdot Q}
\end{aligned}
$$

where, $\Delta \mathrm{p}$ is the pressure drop through the turbine (calculated after taking the average pressure at the rotor inlet and the rotor exit), $\rho$ is the density of the fluid, $\mathrm{T}$ is the rotor torque, $\omega$ is the turbine angular velocity (in $\mathrm{rad} / \mathrm{sec}$ ) and $\mathrm{Q}$ is the flow rate calculated by $Q=V \cdot A$. Here, $\mathrm{V}$ is the flow absolute velocity and $\mathrm{A}$ is the area of the flow that takes into consideration the blade tip clearance.

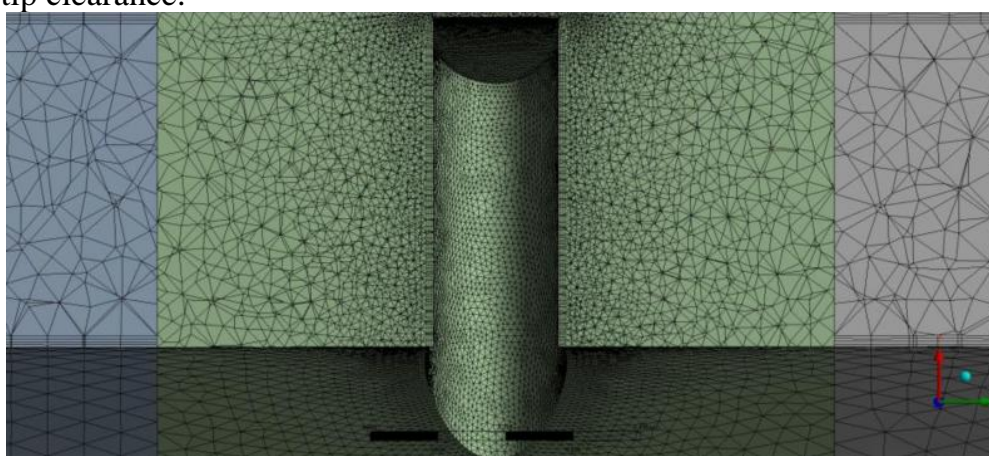

(a)

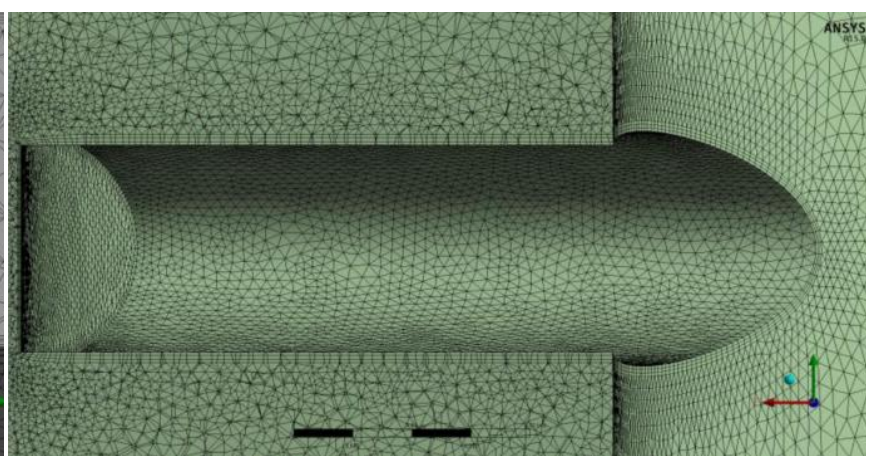

(b)

Figure 3 a) Computational grid and b) grid detail around the blade

\section{RESULTS AND DISCUSSION}

Figure 4 presents the variations of the torque coefficient, the pressure coefficient and the turbine efficiency in relation to the flow coefficient $(\Phi=V / U)$ for both Wells turbine geometries under consideration. Flow coefficient is defined as the ratio of the flow absolute velocity to the blade tangential velocity $\left(U=\omega \cdot r_{t}\right)$. Each operating condition is shown in Figures 4, 5 and 6 , it is noted that stall occurs in the flow rate where the first drop in torque is observed. From the efficiency values it appears that it is even possible to achieve almost $60 \%$ energy extraction from the air flow using the Model B turbine. This value is comparable to the performance ratios presented in the work of other researchers (Falcao, 2010; Lopez et al., 2013). Comparing the results of Model A with these of the literature (Dhanasekaran et al., 2005; Carija, 2012) showed identical behaviour of the turbine, in terms 
of stall thus the present work simulations may be characterized as reliable. Figure 7 shows this comparison of results in terms of efficiency.

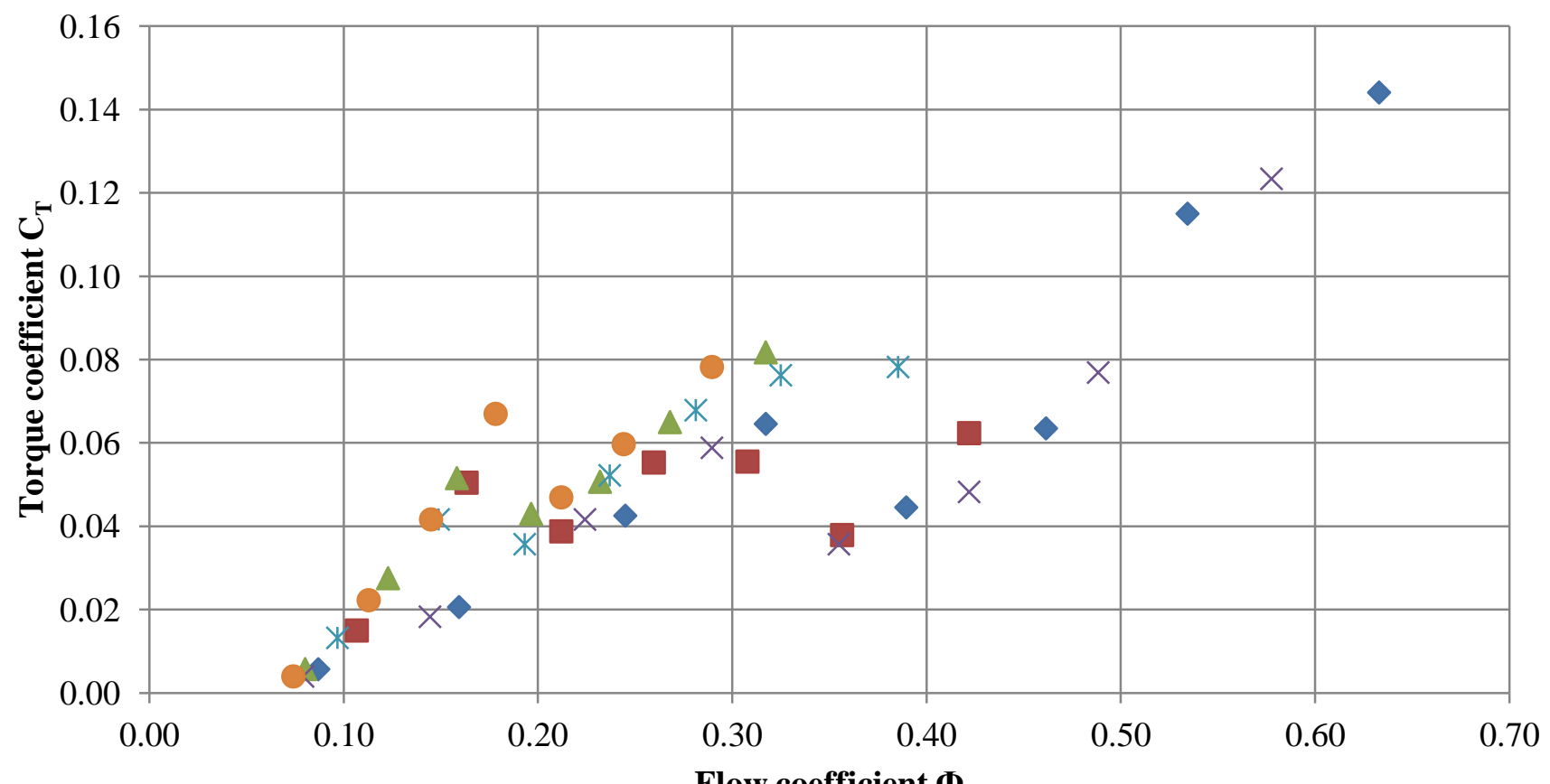

Flow coefficient $\Phi$

- Model A @ 2000 rpm $\square$ Model A @ 3000 rpm $\triangle$ Model A @ 4000 rpm

×Model B @ 2000 rpm * Model B @ 3000 rpm • Model B @ 4000 rpm

Figure 4 Rotor torque coefficient diagram versus flow coefficient for various rotational speeds

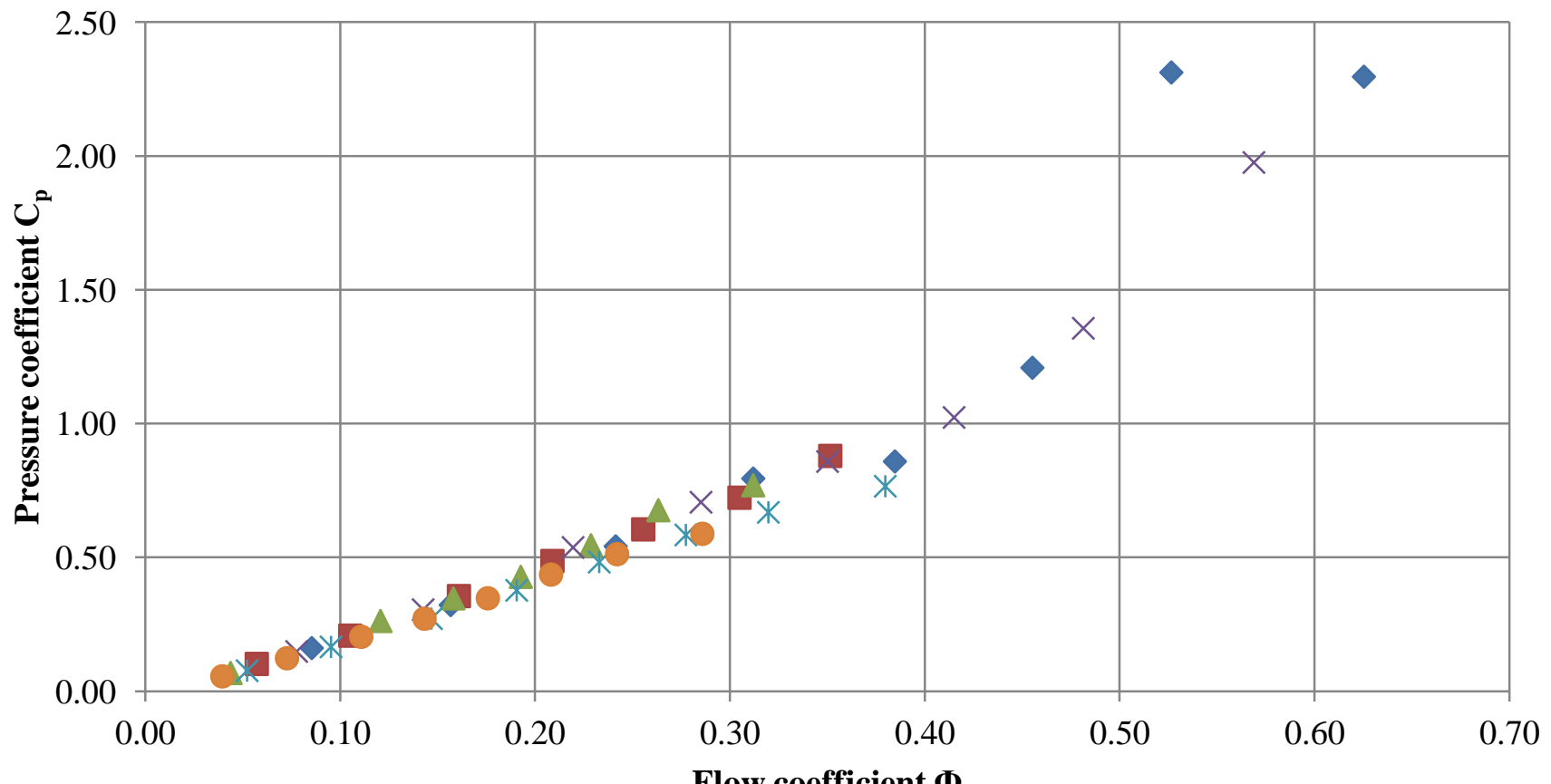

Flow coefficient $\Phi$

- Model A @ 2000 rpm $\square$ Model A @ 3000 rpm $\triangle$ Model A @ 4000 rpm

×Model B @ 2000 rpm * Model B @ 3000 rpm ・ Model B @ 4000 rpm

Figure 5 Pressure coefficient diagram versus flow coefficient for various rotational speeds 


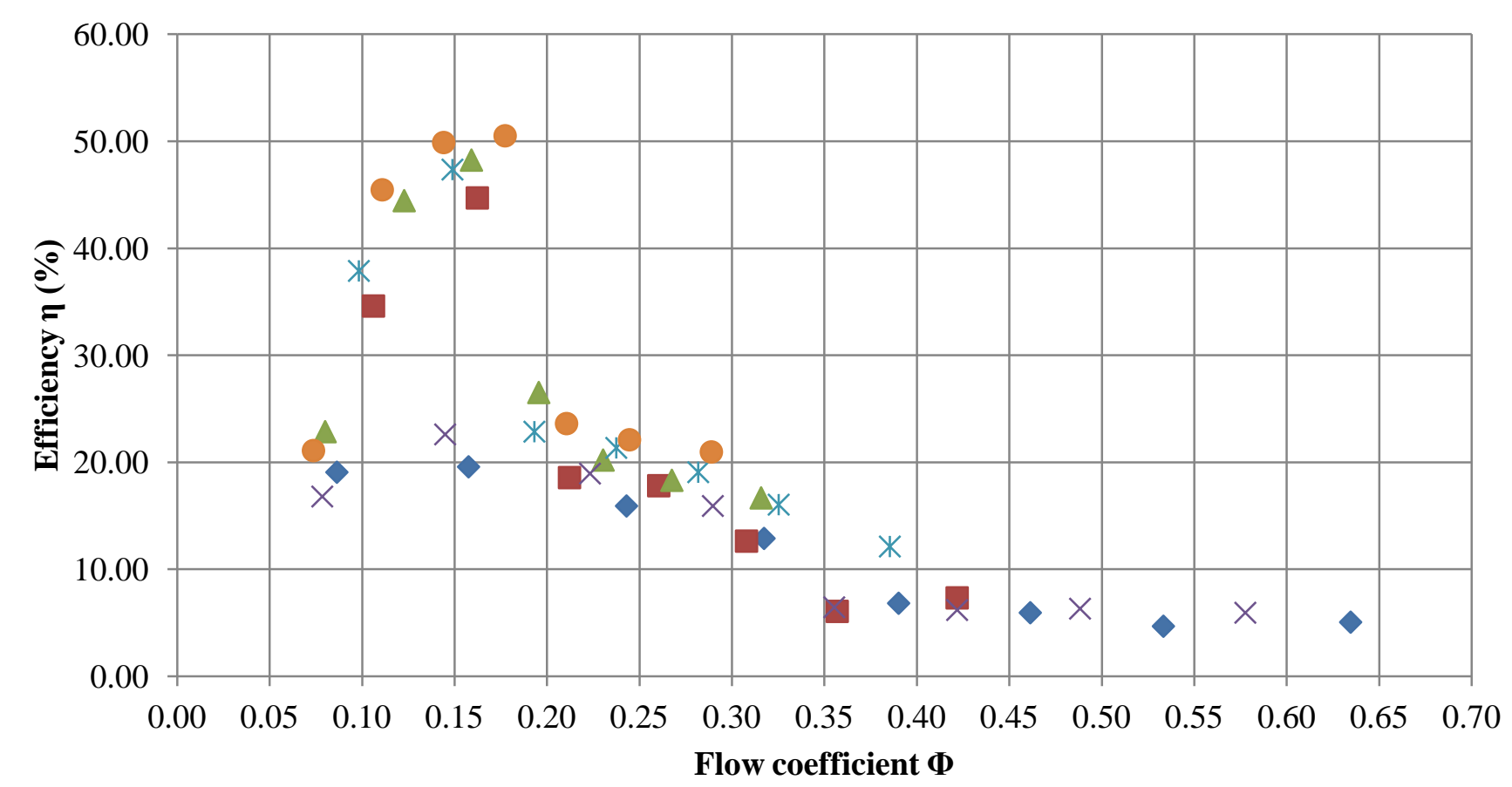

• Model A @ 2000 rpm $\square$ Model A @ 3000 rpm $\triangle$ Model A @ 4000 rpm ×Model B @ 2000 rpm * Model B @ 3000 rpm •Model B @ 4000 rpm

Figure 6 Turbine efficiency diagram versus flow coefficient for various rotational speeds

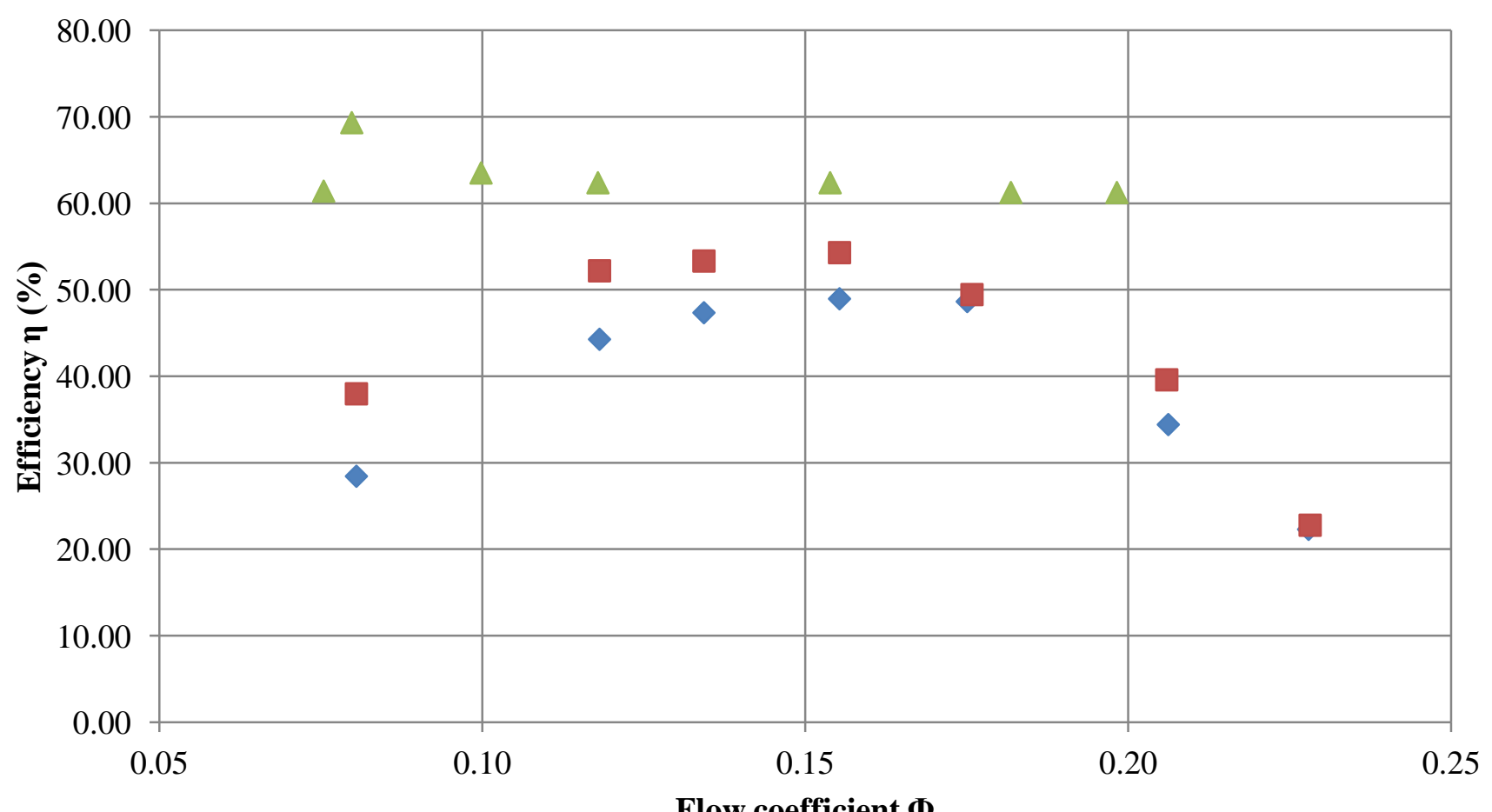

$\diamond \mathrm{SST}$ (present work) $\quad$ SST (literature) $\triangle$ experimental (literature)

Figure 7 Comparison between Model A efficiency and the efficiency of a similar model studied computationally and experimentally by other researchers (rotational speed $4500 \mathrm{rpm}$ ) 


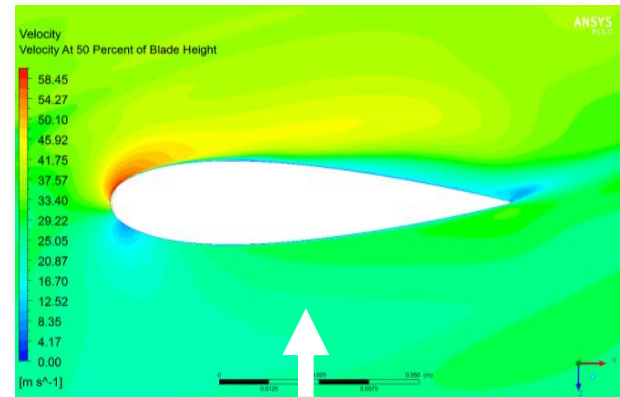

(a)

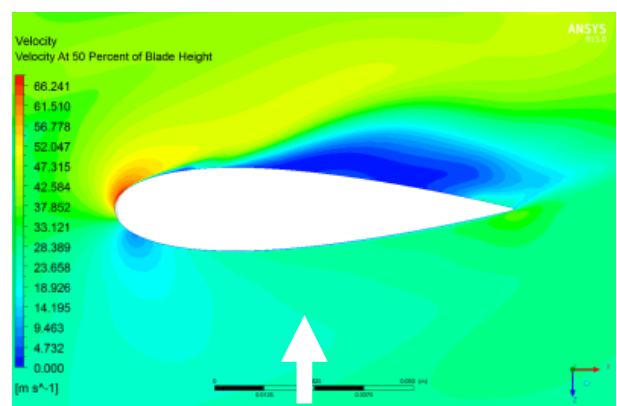

(b)

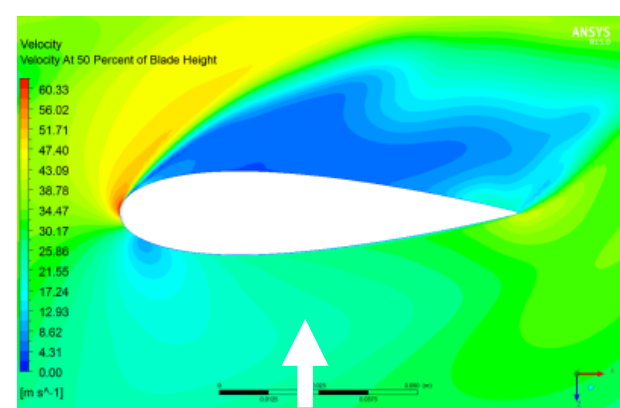

(c)

Figure 8 Flow field contours of the relative velocity for inlet velocity of a) $6.5 \mathrm{~m} / \mathrm{s}$, b) $8.5 \mathrm{~m} / \mathrm{s}$, c) $10 \mathrm{~m} / \mathrm{s}$ at $50 \%$ of the blade height

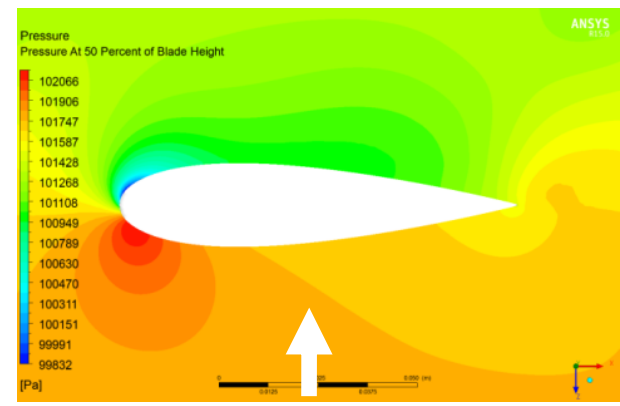

(a)

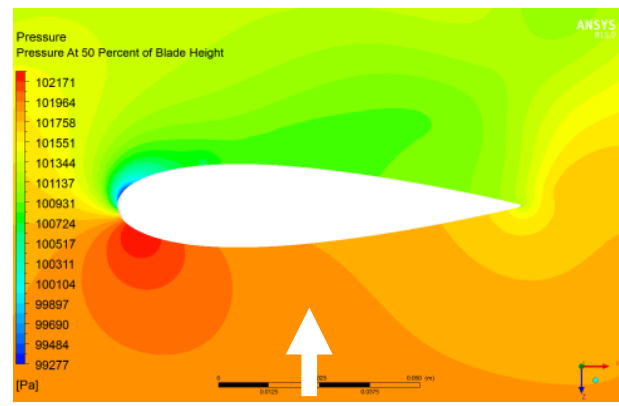

(b)

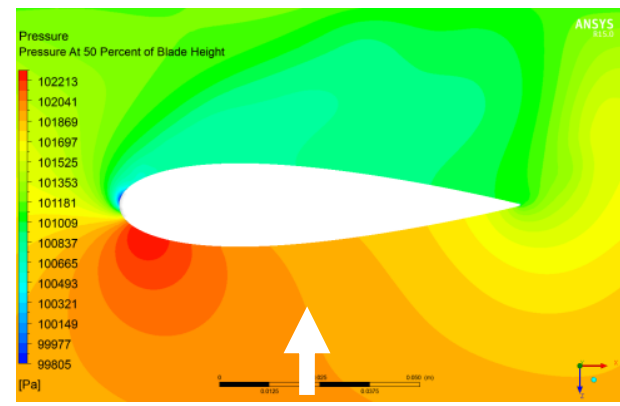

(c)

Figure 9 Flow field contours of the static pressure for inlet velocity of a) $6.5 \mathrm{~m} / \mathrm{s}$, b) $8.5 \mathrm{~m} / \mathrm{s}$, c) $10 \mathrm{~m} / \mathrm{s}$ at $50 \%$ of the blade height

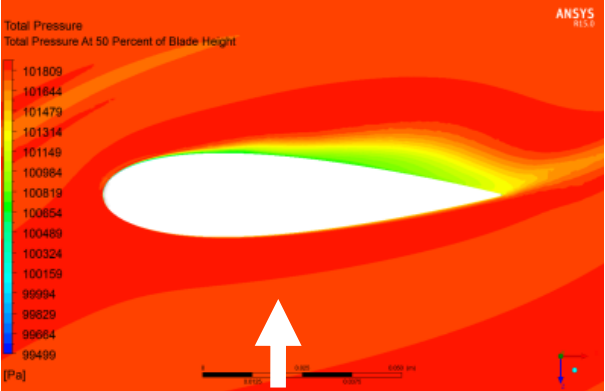

(a)

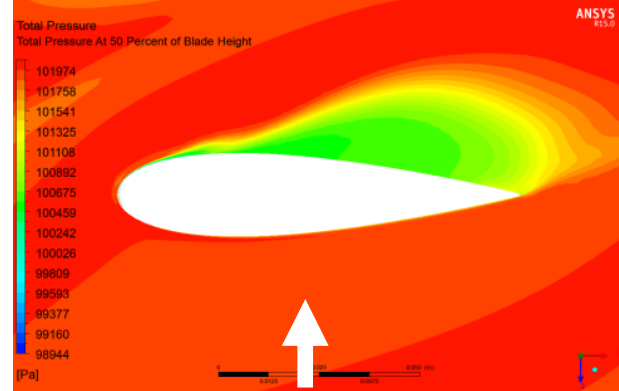

(b)

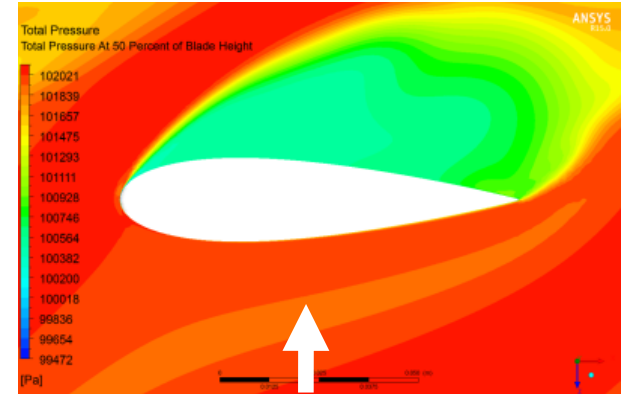

(c)

Figure 10 Flow field contours of the total pressure for inlet velocity of a) $6.5 \mathrm{~m} / \mathrm{s}$, b) $8.5 \mathrm{~m} / \mathrm{s}$, c) $10 \mathrm{~m} / \mathrm{s}$ at $50 \%$ of the blade height

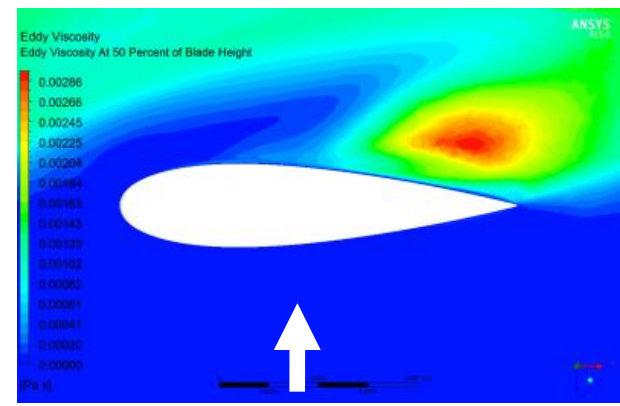

(a)

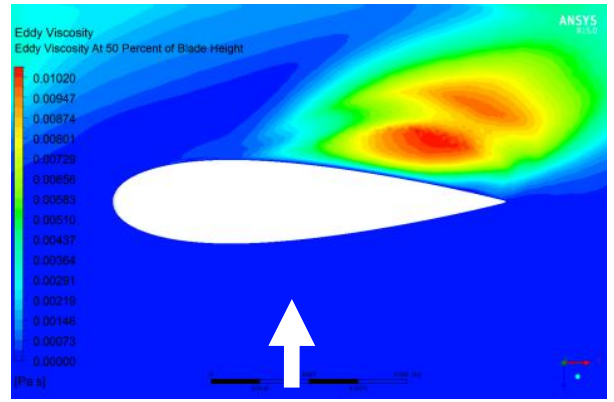

(b)

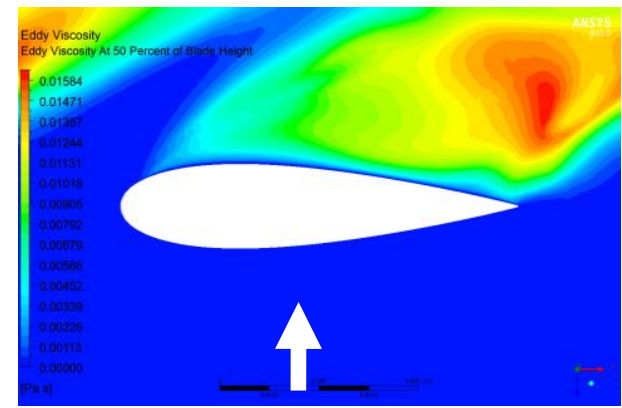

(c)

Figure 11 Flow field contours of the eddy viscosity for inlet velocity of a) $6.5 \mathrm{~m} / \mathrm{s}, \mathrm{b}) 8.5 \mathrm{~m} / \mathrm{s}, \mathrm{c}$ ) $10 \mathrm{~m} / \mathrm{s}$ at $50 \%$ of the blade height 
A thorough examination of the computational results provides useful conclusions on the flow field development through the rotor blades. Figures 8-11 present flow field contours of velocity, static pressure, total pressure and eddy viscosity (as a turbulence metric) on a plane positioned at $50 \%$ of Model B blade height. The rotor speed is set at $2000 \mathrm{rpm}$ and the inlet velocity is $6.5,8.5$ and $10.5 \mathrm{~m} / \mathrm{s}$. Stall appears at inlet velocity of $8.5 \mathrm{~m} / \mathrm{s}$. Flow development contours provide a better understanding of this behavior since at $8.5 \mathrm{~m} / \mathrm{s}$ the detached flow area is significantly large, it starts from the airfoil point of maximum thickness and the flow remains detached. For velocity equal to $6.5 \mathrm{~m} / \mathrm{s}$ the separation bubble is limited to a small portion of the airfoil near the trailing edge flow while at $10.5 \mathrm{~m} / \mathrm{s}$ the flow separation starts from the leading edge and completely separated. Flow separation is also presented by the pressure field around the airfoil. The low pressure values indicate that strong separation takes place on the suction side. Turbulence is enhanced by the turbulence generated mainly by the rotor blade wakes. Figure 12 presents the torque coefficient calculated under unsteady conditions with a steady inlet velocity of $6.5 \mathrm{~m} / \mathrm{s}$ and a rotating speed varying from almost zero rpm to $4000 \mathrm{rpm}$. Figure 13 presents the time dependent simulation results concerning the torque coefficient as a function of the time varying inflow velocity. The frequency of the velocity variation is $0.167 \mathrm{~Hz}$. Figure 14 presents the torque coefficient versus the flow coefficient. Turbine starting diagrams feature a rotating speed range from 705 to $805 \mathrm{rpm}$ where torque is almost zero. In this range it is very likely that the crawling phenomenon will occur, which expresses the inability of the turbine to pass through the area where the tangent force coefficient receives negative values and which, therefore, can lead the turbine to low speed operation.

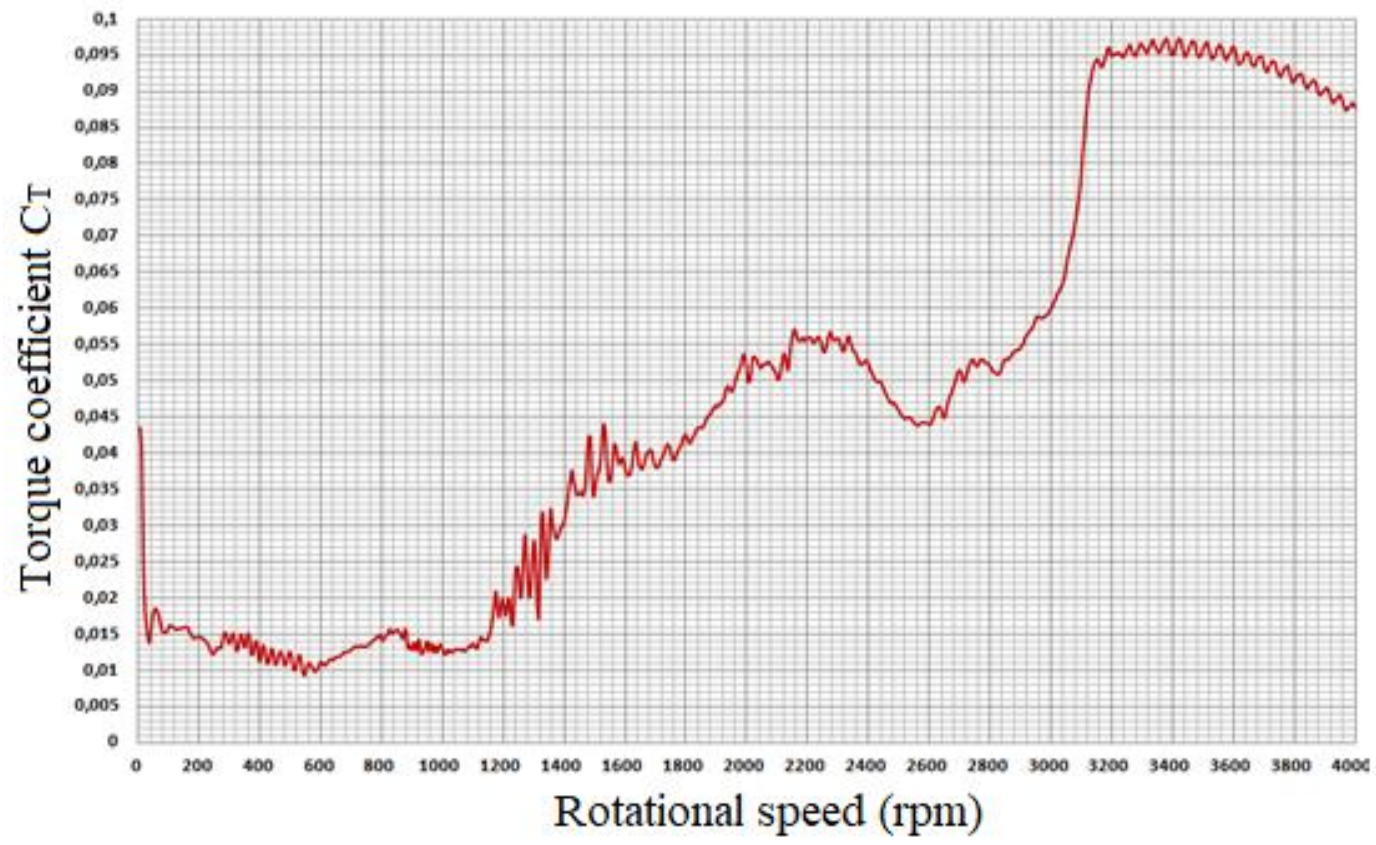

Figure 12 Starting characteristics of the Model B rotor (inlet velocity equal to $6.5 \mathrm{~m} / \mathrm{s}$ )

In Figure 13 it can be observed that the torque curves are not exactly the same. The curve on the left side, which results while the air flow comes from the upstream direction, has a greater pick than the curve on the right (which results when the airflow comes from the opposite direction). Theoretically, the two parts of the curve should be identical, but in practice the inertia of the air flow and the way in which the boundary layer develops on the blades leads to different results. However, the average torque has a positive value. Based on the way in which the hysteresis phenomenon is shown in Figure 14, it is observed that during the transition from the accelerating to decelerating air flow state, a clockwise closed loop appears. This closed loop is directly related to the existence of flow detachment phenomenon and the occurrence of the stall. Other researchers (Thakker and Abdulhadi, 2008), however, also observed an inverted closed loop, which is not directly related to the occurrence of extreme detachment phenomena but it is attributed particularly to the boundary layers development. 


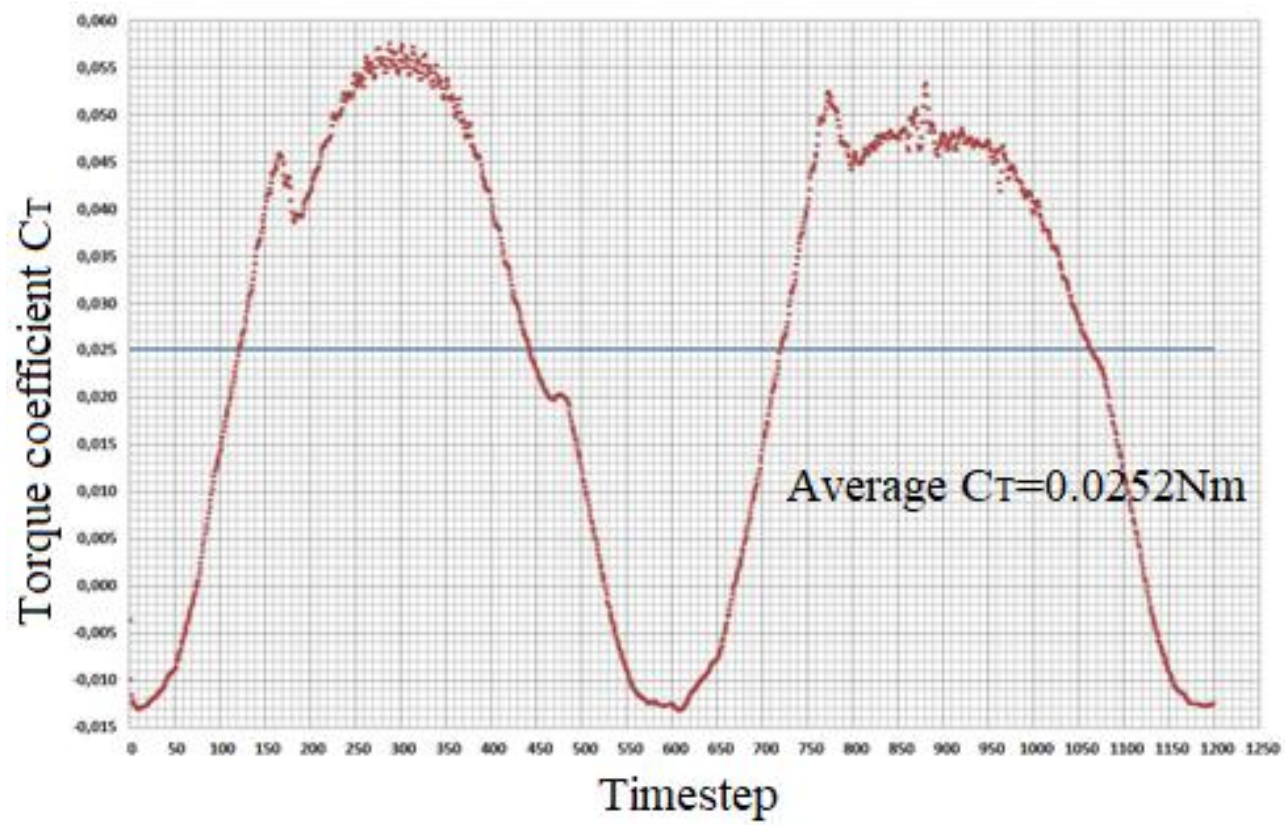

Figure 13 Time dependent torque diagram and under sinusoidal inlet velocity variation (frequency $0.167 \mathrm{~Hz}$ and rotational speed $2000 \mathrm{rpm}$ )

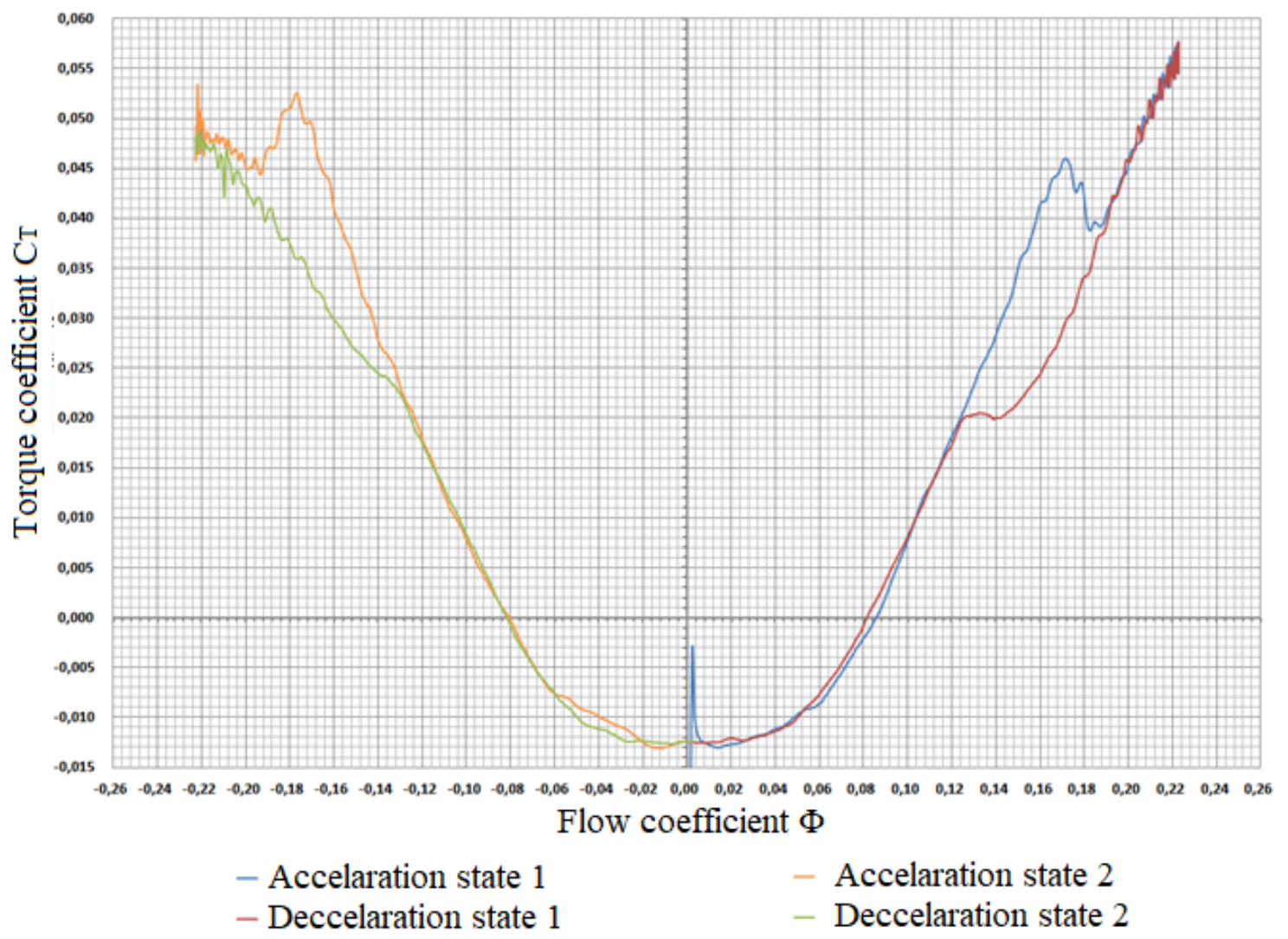

Figure 14 The hysteresis phenomenon under sinusoidal inlet velocity variation (frequency $0.167 \mathrm{~Hz}$ and rotational speed 2000 rpm)

\section{EXPERIMENTAL SETUP}

In order to further investigate the operation of Model B which was designed and analysed computationally, an in-house experimental rig was developed. A 3D printed prototype was used and a special device was designed in order to produce airflow identical to that produces in an OWC (Fig. 15). 
The experimental results show similar trends to those of the computational analysis. The estimated efficiency was greater than $68 \%$, while in the literature the maximum experimental efficiency recorded is approximately $75 \%$. Figure 16 shows the efficiency of the experimental turbine, after testing it in a wind tunnel, changing its rotational speed from 300 to $900 \mathrm{rpm}$. For turbine speeds equivalent to 500 and $700 \mathrm{rpm}$, the efficiency was almost $68 \%$, while for $300 \mathrm{rpm}$, the largest operating range was achieved with a maximum efficiency of approximately $67 \%$.

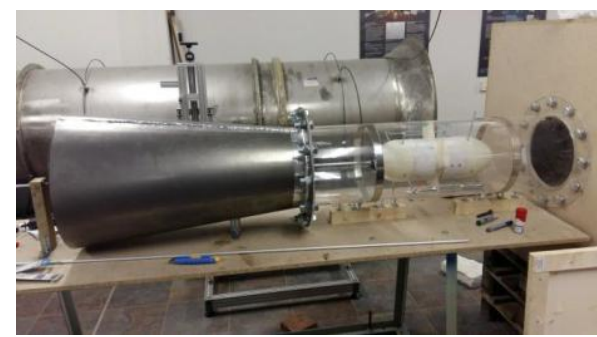

(a)

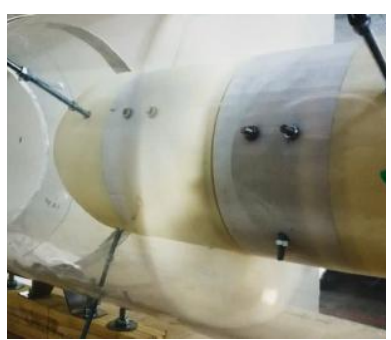

(b)

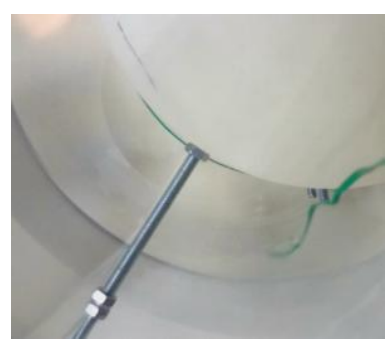

(c)

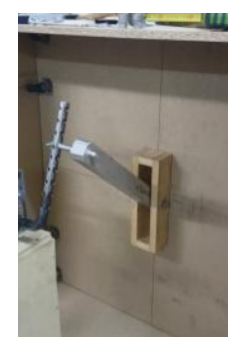

(d)

Figure 15 a) Overview of the test rig, b) the Wells turbine rotor, c) the hub was carried by adjustable supports in order to control the unbalancing between tests d) detail of the piston mechanism

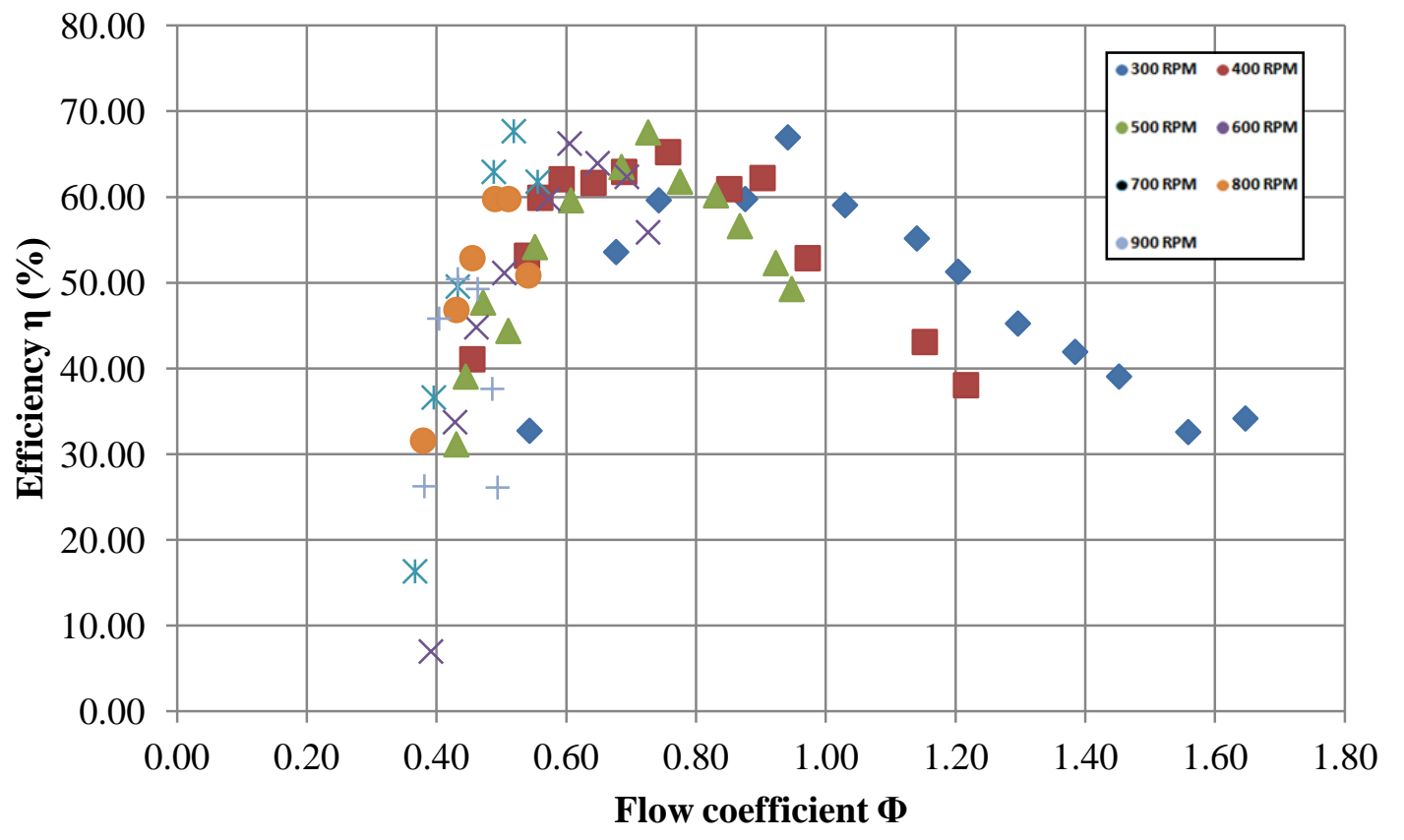

$\diamond 300 \mathrm{rpm} \quad 400 \mathrm{rpm} \quad \triangle 500 \mathrm{rpm} \times 600 \mathrm{rpm} \quad * 700 \mathrm{rpm} \quad 800 \mathrm{rpm} \quad+900 \mathrm{rpm}$

Figure 16 Rotor efficiency for rotational speeds varying from 300 to 900 rpm

\section{CONCLUSIONS}

In the present work, two different Wells turbine geometries were designed in order computationally and experimentally study their flow behavior and performance. Their computational analysis was performed using the commercial software ANSYS CFX.

The computational simulations provided results that indicate the ability of the Wells turbine to produce significant amounts of energy under either steady or unsteady flow conditions. In particular, the maximum efficiency achieved was approximately equal to $48 \%$ for Model A (4000 rpm) and 51\% for Model B (4000 rpm), with Model B presenting a larger operating range. In general, as far as the operating range of the Wells turbine is concerned, it is admittedly limited; however this was expected as it was also found by other researchers. In addition, it has been shown that these results have a relative accuracy. In terms of computational simulations under unsteady flow conditions, the Wells turbine appears to work as expected for a sinusoidal changing inflow speed, producing a time-varying torque with an average positive torque value, while the starting characteristics of the turbine proved very useful for explaining the phenomena that took 
place during the experimental process. The hysteresis phenomenon studied by other researchers also appears to be present in the simulations of this work.

An experimental rig was designed and constructed. The experimental process showed the ability of the turbine to produce significant amounts of energy. The efficiency for this turbine operation is large and comparable to those of other experimental studies. The maximum efficiency observed was $68 \%$ when the maximum efficiency found in the literature today is $75 \%$. Although it has not been possible to have a back to back comparison of the experimental and computational results, the experimental results are quite encouraging since a very good efficiency was achieved.

\section{NOMENCLATURE}

$\begin{array}{cl}\begin{array}{cl}\text { Abreviations } \\ \text { OWC }\end{array} & \text { Oscialting Water Column } \\ \text { RANS } & \text { Reynolds Averaged Navie } \\ \text { SST } & \text { Shear Stress Transport } \\ \text { Greek characters } & \\ \alpha & \text { absolute flow angle } \\ \beta & \text { relative flow angle } \\ \eta & \text { Efficiency }(\%) \\ \rho & \text { Density }(\mathrm{kg} / \mathrm{m} 3) \\ \Phi & \text { Flow coefficient }(-) \\ \omega & \text { Angular velocity }(\mathrm{rad} / \mathrm{sec}) \\ & \\ \text { Latin characters } & \\ \mathrm{A} & \left.\text { Area (m }{ }^{2}\right) \\ \mathrm{C}_{\mathrm{p}} & \text { Pressure coefficient }(-) \\ \mathrm{C}_{\mathrm{T}} & \text { Torque coefficient }(-) \\ \mathrm{p} & \text { Pressure }\left(\mathrm{N} / \mathrm{m}^{2}\right) \\ \mathrm{Q} & \text { Flow rate }\left(\mathrm{m}^{3} / \mathrm{s}\right) \\ \mathrm{r}_{\mathrm{t}} & \text { Tip radius (m) } \\ \mathrm{T} & \text { Torque }(\mathrm{Nm}) \\ \mathrm{U} & \text { Tangential velocity }(\mathrm{m} / \mathrm{s}) \\ \mathrm{V} & \text { Absolute velocity }(\mathrm{m} / \mathrm{s}) \\ \mathrm{W} & \text { Relative velocity }(\mathrm{m} / \mathrm{s}) \\ & \end{array}$

\section{REFERENCES}

T. Setoguchi, M. Takao (2006). Current status of self rectifying air turbines for wave energy conversion. Energy Conv. Manag., 47 (2006), pp. 2382-2396.

Falcao, A. F. O., Henriques, J. C. C. (2016). Oscillating-water-column wave energy converters and air turbines: A review. Renewable Energy, 85, pp. 1391-1424.

Ying Cui, Zhen Liu, Xiaoxia Zhang and Chuanli Xu (2019).

"Review of CFD studies in axial-flow self-rectifying turbines for OWC wave energy conversion". Ocean Engineering, Volume 175, Pages 80-102.

Wells AA. (1976). Fluid driven rotary transducer. British patent spec No. 1595700.

Carija, Z., Kranjcevic, L., Banic, V., Cavrak, M. (2012). Numerical analysis of Wells turbine for wave power conversion. Engineering Review 32(3), pp. 141-146.

Dhanasekaran, T. S. and Govardhan, M. (2005). Computational analysis of performance and flow investigation on wells turbine for wave energy conversion. Renewable Energy, 30(14), pp. 2129-2147.

Falcao, A. F. O. (2010). Wave energy utilization: a review of the technologies. Renew. Sust. Energy Rev., 14(3), pp. 899918.

Lopez, I., Andreu, J., Ceballos, S., Martinez de Alegria, I., Kortabarria, I. (2013). Review of wave energy technologies and the necessary power-equipment. Renew. Sust. Energy Rev. 27, pp. 413-434.

Menter, F. R. (1994). Two-Equation Eddy-Viscosity Turbulence Models for Engineering Applications. AIAA Journal, 32(8), pp. 1598-1605.

Thakker, A., Abdulhadi, R. (2008). The performance of Wells turbine under bi-directional airflow. Renewable Energy, 33 (11), pp. 2467-2474. 